\title{
EXPLORING FRAGMENTED WORLDS: HEMINGWAY AND HOPPER
}

\author{
Gabriela TUCAN* \\ West University of Timişoara, Romania
}

\begin{abstract}
In Edward Hopper's disquietingly familiar realist paintings, isolated individuals experience the urban drama of everyday life in the early decades of the twentieth century. Paintings such as Sunday, Automat, Drug Store, Chop Suey, Nighthawks, and Summer Evening are populated by enigmatic and anonymous figures inhabiting equally anonymous locations. Despite Hopper's preference for the visual medium to express the fragmented times of modernity, his paintings provide analogies to Hemingway's unsentimental short stories of the 1920s. Underlying both Hopper's paintings and Hemingway's stories, however, is a common story of human disjointedness that is their artistic response to a modern fragmented society and culture. Hemingway's short stories “Cat in the Rain,”“'The Killers,”and “A Clean, Well-Lighted Place,” among many others, depict an equally alienating landscape of isolation and loneliness, reflecting the uncertainties of the historical times. Finally, my article will examine the disrupted narrative subtexts in a series of visual works by Hopper and short stories by Hemingway. I argue that their broken narratives create an unvoiced paradox: there is an openness to interpretation, despite the structural and formal disruptions present in these two artistic media.
\end{abstract}

Keywords: Hemingway, Hopper, modernism, fragmentation, narrative disruptions, modern city life, urban imagery

\section{INTRODUCTION}

Edward Hopper's Nighthawks painted in 1942 is reminiscent of Hemingway's short story "The Killers," which the latter wrote in 1927 and first published in Scribner's Magazine. Hopper admired Hemingway and was inspired by his story, but it can be argued that they both master successfully the technique of withholding information from readers and viewers, the elliptical style, and the

\footnotetext{
*gabriela.tucan@e-uvt.ro
} 
aesthetics of implicitness. In their artistic works, every word or image counts. Both artists conceal and reveal only a minimum amount of information, creatingan unspoken tension. Thematically, they both depict "slices of life" in a dry tone and with economical means. Nighthawks and "The Killers" portray men and women being waited on at a diner late in the evening. Hopper's interior, a clear allusion to Hemingway's crime story, shows three stray customers being served by a waiter, but what is striking is that it emphasizes the contrast between the artificial light inside and the threatening dark atmosphere outside. The same sharp contrast between darkness and light, and between artificial and natural light, must have appealed to Hemingway as he described his two black-clad "killers", $\mathrm{Al}$ and Max, who enter a small lunchroom in a town in Illinois where the action takes place, threaten the owner at gunpoint, and wait for the arrival of Ole Andreson, a Swedish prize-winning boxer.

This essential feature of using light both reveals and conceals the characters in Hopper's painting and Hemingway's short story, which indicates that, technically, they both approach art in a similar manner. In addition, they share an interest in realistic details and urban imagery. Their alienating landscapes of isolation and loneliness reflect more than a shared artistic preference.They also clearly reflect the troubled historical times in which they lived. They both experienced the 'Roaring Twenties' but also the traumatic unsettling times between the two World Wars. As fully developed artists, Hemingway and Hopper express their personal visions of American city life in the wake of World War II. Hopper's unappealing streets of New York City, with its unembellished public places, his interiors lit by electricity projecting an unbearably sinister feeling, all accurately portray twentieth century city life and the fragmented nature of modernity. Hemingway's often unnamedcharactersare closed off within themselves, isolated in a confusing intimate world and sometimes exposed to the impersonality and banality of city life. The dialogue between Hopper's realist paintings and Hemingway's unsentimental short stories in the postwar era must have been fuelled by the particular ability the short story has to encapsulate the experience of modernity. Regarded as a "quintessentially modernist form" (Head xi), the genre of the short story incorporates a cluster of "disunifying devices" (Head $\mathrm{x}$ ), generally involved in the modernist revolution in fiction, but which also account for the formal and narrative disruptions developed by the short story. Features such as deliberately indeterminate and incomplete narratives, stylistic economy, textual density, and intentional narrative discontinuity have a seminal role not only in the modern phase of the short story, but also in capturing the fleeting perceptions of urban modern life. The emerging form of the short story shares with the modern art of painting a crucial modernist preoccupation: the perception of the modern urban life as a fragmented reality. 
If modernity is perceived as the world of fragmentation, the modern subject is doomed to wander in an alienating urban space in which social interaction is scant and impersonal. However, impersonal and meaningless is also the private world. These tendencies of fragmentation occurring in both public and private spaces are adapted and modified by the two modern American artists. They incorporate fractures and gaps in their works that readers and viewers need to close themselves through close reading and viewing. If Hemingway and Hopper reflect the progressive fragmentation of modern life, a time of great fear and anxiety in the postwar America, their shared story of human disjointednessis their artistic response to the episodic nature of the modern society and culture. I argue that Hemingway's and Hopper's "sister arts" create a confusing tension and put forth an unvoiced paradox: they are built on a fundamental structural absence but are nonetheless thematically open. In this regard, my article sets out to resolve this paradox and examine the thematic effects emerging from structural fragmentations and formal disruptions.

\section{URBAN IMAGERY IN MODERNIST AMERICAN LITERATURE AND PAINTING}

American modernist writers and painters in the early decades of the twentieth century were committed to the depiction of modern urban life. They responded to the dramatic social changes that accompanied the creation and rise of big cities. At that time, the United States was possibly the culture most affected by the historic shift to a predominantly urban culture: "Perhaps if we broadly say that in the nineteenth century the people of the United States have multiplied fifteen times, and in the same period the population of their incorporated cities and towns has multiplied one hundred and fifty times, we may make at least a start toward grasping the greatness of the thing” (Weinberg et al. 138). Therefore one may argue that American modernist artists largely drew their creative energy from the rapid expansions of cities and the invention of new and more advanced technologies. Accordingly, American urban scenes in literature and painting were adept at presenting the degree of urban development, with urban isolated subjects, inhabiting artificial landscapes and having to cope with unattractive urban realities. In fact, the interest of artists in portraying modern city life resulted from their actual immersion in the modern city and their thorough involvement with modern life. It can be concluded that the modernist movement "was essentially the product of the modernizing societies of the West (including Western Russia), and its favorite environment was the locus parexcellence of all modernizing processes: the modern metropolis. Paris, London, Berlin, Milan, St. Petesburg, New York were its centers” (Ickstadt 379-80). The artistic metropolis with its cinemas, skyscrapers, speedy traffic, cafés and offices, unfriendly 
strollers and isolated pedestrians, radically breaks away from the stability of life before the turn of the twentiethcentury and thematizes the chaotic condition of modernity.

It is evident that literature and the arts that dealt with the new material of the urban scene and explored the energies of city life needed a renewal of language and form, but in the US, the exploration of the vernacular and the regeneration of common speech played a special role in the search for a genuine national expression of the modernism of the early twentieth century. American writers and artists who left the US to familiarize themselves with European modernism, but also those who stayed at home, adapted the new practices and concepts to a national tradition. Although modernism is clearly a European invention, it was rather problematic for American cosmopolites to accept the opposition between their country's cultural backwardness and its technological modernity. Therefore they felt compelled to assert American cultural independence, which, in fact, "meant to uncover what was in front of everybody's eyes or to rediscover and work out what was always already inherently there" (Ickstadt 381). It was precisely the commitment to old American ideals and to new realities and realism that perfectly suited modernized America, a champion-nation of technological modernity. Animated by a growing interest in modern everyday experience, American modernists gave a distinct voice to the celebration of the ordinary and local energies. This is why the modern city is an important literary and artistic locus in American fiction and painting.

The experience of modernity meant that artists were confronted with "the small shocks of urban existence" (Baer 7), which become the focus of the modern "artistic wasteland". There is no doubt that modernists were responsive to the emerging fragmentation and the sense of emptiness that characterized contemporary society from the early twentieth century onwards. As artists of the new realities, American modernist writers and painters were alert to trivial subjects in which the ordinary individual was empowered and played a key role in familiar experiences, but who was also supposed to live in a permanent state of rupture in the city, a symbol of modernity. Implicitly, having to cope with this culture of fragmentation, "many modernist writers strove to reassemble the fragmented city experience through their art” (Keuner 277).

In addition to the experience of change, modernism thus generates a sense of crisis and alienation and endorses discourses on cultural fragmentation, which was a clear change in attitude for modern artists and writers. Keuner (272) associates modern literature with a condition of fragmentation, which he firstly connects with the fragmentation of the social world, subsequently creating a growing gap between public and private spheres, a gap that was primarily experienced by the modern subject living in the city. It is the modern family life, regarded as a threatened enclave, that needs to be protected against the chaotic 
social world. The second important fragmentation is the one leading to the decline of moral discourse in the private world. Artistic representations of the city concentrate mainly on this moral disintegration of urban dwellers and their psychological disorientation. It seems that the chaos of modern life is responsible for the fragmentation of values and the disintegration of the moral discourse. This means that the urban subject is threatened by the growing impersonality of social life and by the potential danger of losing control over one's own life. "The impersonal world of modern consumer society is not just an empty, meaningless one but paradoxically also an environment teeming with uncontrollable perceptions and multiform practices, a 'chaos of impressions and interactions' (Frisby [1992], 71). The modern subject's reaction [...] is to focus increasingly on momentary and extremely heterogeneous ways of giving meaning to existence” (Keuner 274).

The analysis of the dehumanized self of the urban individual is one of the prevailing topics of the modernist short story. If one considers itsfragmented nature and disjointed discourse, it can be argued that the short story has a fundamentally modernist form which resonates with the disordered subjectivity of modernity: "The short story is a fragmented and restless form, a matter of hit and miss, and it is perhaps for this reason that it suits modern consciousness" (Gordimer 265). Moreover, it allows an in-depth exploration of the subjectivity of isolated individuals. In his study on short fiction, The Lonely Voice, Frank O'Connor argues that short stories do not normally create "heroes" or models that can be followed, but instead, the world of short fiction is populated by isolated figures "wandering about the fringes of society", dreamers, artists, or lonely idealists. This fictional world is that of "the submerged population", one that differs from writer to writer, but that will always describe a sense of "an intense awareness of human loneliness" (19). Quite clearly, "the lonely voice" of the submerged population prompts a particular attitude of mind used to understand the new reality:

The reality the short story presents us with is the reality of those sub-universes of the supernatural and the fable which exist within the so-called 'real' world of sense perception and conceptual abstraction. It presents moments in which we become aware of anxiety, loneliness, dread, concern, and thus find the safe, secure and systematic life we usually lead disrupted and momentarily destroyed. The short story is the most adequate form to confront us with reality as we perceive it in our most profound moments. (May 142)

Within the social context of the early twentieth century America, there are notable continuities between literature and the visual arts especially when they are illuminated by shared themes emerging from the actualities of the historical period. Both painters and writers were affected by the tensions of a 
new America. Very often the subjects of paintings and literary works revealed the same type of fractures developing beneath the surface of modern life.

\section{HEMINGWAY AND HOPPER}

Two of the most acclaimed American modernists, Ernest Hemingway (18991961), novelist and short story writer, and Edward Hopper (1882-1967), realist painter, were deeply preoccupied with European modernism, with which they became acquianted during their visits in Paris, a locus of artistic energyduring the inter-war period. Henri Matisse (1935) once said that "elsewhere, artists are content to follow where others have led, but in Paris there is the enterprise and the courage necessary to all creative work which has made this city an artistic centre". Yet, Hemingway's and Hopper's art moves beyond an overwhelming European influence by revealing clear signs of a distinctly American artistic style. One striking constant in their works is a thematic consideration of shared subject matters and a love for realistic details. They focus on ordinary aspects of American city life, depict realistically the most unappealing local places, and present unembellished authentic realities. In short, they throw light on the relevance of the new American experience. At the same time, they capture the fragmented character of modern life and the abrupt changes in the modern subject, now involved in distant observation, reserved commentaries, and the pursuit of the authentic self.

Hemingway was clearly not a stranger to the new modernist sensibility, but even so, his "marginal sensibility" makes him a unique and exceptional case. Warren (39) sees the author's particular sensibility in his style of playing down feeling by locating "the poetic, the pathetic, or the tragic" in the "unpromising" individual (e.g. the soldier, the bullfighter, the gangster, the revolutionist, or the sportsman), in an anti-romantic situation. The call for depicting these isolated figures is also prevalent in Hopper's paintings. When his subjects are not entirely absent, they are either involved individually in banal activities or are excluded from civilization, isolated and confined to almost hermetically sealed interiors.

Hopper's and Hemingway's settings are built on a sense of gaps and fissures that are at first perceived and then intensely experienced by their lonely subjects. Both the public and private spaces described by the American short story writer and the American painter reconfirm the presence of isolation and alienation, but they also convey anunsettling sense of mystery and a disturbing tension. I argue that these tensions and mysteries draw their impact from the formal disruptions and structural fragmentariness deliberately adopted in visual and textual terms by the two modernist artists. 


\section{TRAVELLING THROUGH DISJOINTED LANDSCAPES AND TOWNSCAPES}

Hemingway's and Hopper's views on the exterior space are not meant to represent the urban panorama per se, but "to render the shifting internal life of an individual consciousness, to present 'the spasmodic, the obscure, the fragmentary, the failure” (Brooker 25). In Sunday (1926), Hopper focuses on a suburban scene showing a man lost in his own thoughts, who appears small and insignificant against the dark empty buildings behind him. Even though it is a Sunday afternoon when people might be resting, the empty streets and the darkened store windows create the sinister atmosphere I have mentioned in the sections above. Clearly, there is something disquieting in the silence of this afternoon, indicating the life of the unprosperous late 1920s in America, but also indirectly hinting at an invisible bigger force on the point of crushing this lonely individual, an outsider who seems to have been excluded from society. This clear separation between Hopper's human subject and his world speaks volumes about the sense of a fundamental and structural fracture that is pictorially rendered but metaphorically meant to symbolize the alienation of humankind.

A renowned painter of townscapes, Hopper uses in Rooms for Tourists (1945) the same method employed in Sunday, i.e. he fragments "his views into a patchwork of differing optical impressions, by juxtaposition of colours” (Renner 22). It is clear that the contrast between the building's artificially lit interiors and the dark streets outside, projecting once again a sinister feeling, questions the expected comfort and accommodation suggested by "rooms for tourists". s Nobody is to be seen anywhere in the house, despite the bright lights that are on. Scholar Rolf Günter Renner shows this scene to be an ambivalent world in which "the things that comfort us and the things we find unsettling are implicitly shown to have the same origins" (42).

In this series of urban paintings, just as in Sunday and Rooms for Tourists and now in NightWindows (1928), Hopper emphasizes the demarcation line between dark exteriors and mysteriously lit interiors. It is, however, Night Windows that creates a more overwhelming sensation of horror and herethe security of the home is questioned. The voyeuristic perspective employed by Hopper allows his viewers to enter the intimate world of the woman who appears indoors. Nevertheless, the viewpoint remains impersonal as it originates in the impersonality of city life, which means that viewers are invited to contemplate only indirectly the indoor scene but are not allowed to experience it directly. This dull home showing banal aspects of everyday life is clearly not embellished by Hopper. Despite this, he is able to endow his places with an unspoken tension, that, as shown already, reflects the fragmentary nature of modern life. 
Similarly, Hemingway's "Hills like White Elephants" (1927)is full of confusing tension and conflict, both rendered in his characteristically detached journalistic method of description. Unlike Hopper's lone subjects, Hemingway describesan American couple in Spain who sit at a table in a hot and dusty railway station, waiting for their connecting train to arrive. In spite of the fact that readers are given little context for the banal dialogue, the woman, Jig, suggests out of the blue that the hills across the valley "look like white elephants," but the man is unresponsive. His inability to communicate is evidence of their failed relationship, not to mention that this also indicates the anguish of the partners' inner lives. The couple's gradual fragmentation is also consistent with the general vision of the contemporary 1920s, together with its prevailing mood of disillusion stemming most probably from the violence of the First World War.

The reader's gaze on the "two lines of rails in the sun" is soon deflected to the gaps and pauses in the exchange between the two partners that have dramatic communicative values. These potentially symbolic silences indicate the woman's smouldering anger and frustration, as sheis unable to articulate what exactly plagues their relationship. Hemingway's artful technique of implication allows his readers to deduce that the man's mentioning of "an awfully simple operation" may be an abortion that the partners are both considering. Critics have interpreted the woman's comparison ("hills look like white elephants") as a pointer to her state of mind. Perhaps her comparison hints to the ordinary phrase of "white elephants" as worthless objects. The white elephant can be her unwanted pregnancy.

The hills across the valley of the Ebro were long and white. On this side there was no shade and no trees and the station was between two lines of rails in the sun. Close against the side of the station there was the warm shadow of the building and a curtain, made of strings of bamboo beads, hung across the open door into the bar, to keep out flies. The American and the girl with him sat at a table in the shade, outside the building. It was very hot and the express from Barcelona would come in forty minutes. (Hemingway199)

The sense of fissure in Hemingway's "Hills like White Elephants" as a means of portraying the early twentieth century life is replicatedalmost identically in Hopper's Summer Evening (1947). Like in Hemingway's short story, it shows a couple standing outside, on the porch of an ordinary house. The sterile setting plays a crucial role here, too. It is the overhead light of this uninviting wooden house, painted in cold colours, with its empty porch, that brims with potentially symbolic meaning. The ghostly white nuances are reflected on the two figures, as if they were on a stage, seemingly defenceless in the limelight. Their body language is reminiscent of Hemingway's dramatic focus on the brief and concise dialogue in "Hills like White Elephants." While 
the girl seems lost in her thoughts, the man rests on the railing, just next to her, but not touching. The physical empty space between them shows there is something missing in their relationship. This scene is viewed and fantasized upon by a voyeur who witnesses once again the sense of alienation at a smaller scale. Nevertheless, the painting hints at Hopper's overall aesthetic scheme: his awareness of the troublesome silence in the observation of the everyday. As one critic observes, "The rigorous structure of his paintings, their limited subject matter and Hopper's experimental use of light create an impression of calm and concentration which can itself be seen as a response to society" (Renner 85).

There is a perceived similarity between the female characters in "Hills"and "Cat in the Rain"(1925). In the latter, Hemingway keeps the storyline extremely short and simple. Nothing much seems to happen: an American couple spends their holiday in an Italian hotel. In the hotel room, the husband keeps himself busy reading while the wife stands at the window and looks for more excitement in the square opposite their room. The wife, also called the American girl, sees a cat wandering about in the dripping rain and suddenly decides to fetch the cat and care for it: "There were only two Americans stopping at the hotel. They did not know any of the people they passed on the stairs on their way to and from their room. Their room was on the second floor facing the sea. It also faced the public garden and the war monument" (Hemingway 107).

In the reception lounge she meets the receptionist, they exchange a few words, and then she goes out into the courtyard, but the cat has already gone. While she is still looking for the missing cat, an umbrella opens behind her. The hotel keeper sends a maid to attend to the wife. His gesture may be triggered by the official standard of the hotel, assisting clients, but it may also be a sign of implicit friendship. In the short exchange between the wife and the hotel's maid, the American girl repeatedly stresses her utmost desires:

'Ha perduto qualche cosa, Signora?'

'There was a cat,' said the American girl.

'A cat?'

'Sì, il gatto.'

'A cat?' the maid laughed.' 'A cat in the rain?'

'Yes,' she said, 'under the table.' Then, 'Oh, I wanted it so much. I wanted a kitty.' (Hemingway 108)

First, the wife uses the word cat, then kitty, normally used by children, implying that she needs more protection and attention, as a child would. When both the wife and the maid return to the hotel lounge, "the padrone bowed from his desk". Here, there is a change of focus on the American girl's thoughts, revealing how she feels when the hotel's owner bows "from his desk": "Something felt very small and tight inside the girl. The padrone made her feel 
very small and at the same time really important. She had a momentary feeling of being of supreme importance" (Hemingway 108). Then, the girl starts indulging in momentary fantasies, imagining herself an important figure for someone, signalling a search for an alternative identity for herself. It is this contradictory feeling - a mix of ordinariness and self-importance - that suddenly changes her perspective on her identity. Her attitude greatly resembles the behaviour of a child in the same circumstances. She is no longer the wife but "the American girl" who apparently feels attached to the hotel keeper, the only one to offer her some comfort. Back in the hotel room, the wife finds her husband engrossed in reading. She tells him how much she wants to have a cat and several other things: “'I wanted it so much,' she said. 'I don't know why I wanted it so much. I wanted that poor kitty. It isn't any fun to be a poor kitty out in the rain,'” (Hemingway 108) but the husband doesn't reply and readily resumes his reading. The description of the wife's and the husband's behaviour is indicative of their emotional set-up and emphasises how their reactions mirror the actual state of their marriage. In the brief dialogue with the husband, the intense tension builds up gradually, indicating that the woman's desire to have "that poor kitty" is not altogether a whim:

The American wife stood at the window looking out. Outside right under their window a cat was crouched under one of the dripping green tables. The cat was trying to make herself so compact that she would not be dripped on.

'I'm going down and get that kitty,' the American wife said.

'I'll do it,' her husband offered from the bed.

'No, I'll get it. The poor kitty out trying to keep dry under a table.'

The husband went on reading, lying propped up with the two pillows at the foot of the bed. (Hemingway 107)

At some point in her increasingly idiosyncratic monologue, she seeks confirmation from her husband that he shares her fantasy, but she doesnot really listen to his brief and uninteresting answers. Afterwards, the wife wilfully resumes her rather absurd one-sided dialogue by making suggestions, as to herself, of changes in her life, a series of apparently futile transformations (a change in her hairstyle, dinner by candles and silverware, new clothes, a kitty to look after).

The woman's personal isolation is understated but nonetheless very much present in this story. The sense of isolation is also rendered in Hopper's realist urban scene of a Drugstore (1927). The painter starts from a very common city sight but attaches to it the fading glamour found accidentally in one of the few places which sends an optimistic message in a world that seems deserted and dark. Against the dull and poorly lit streets, the pharmacy's window is painted in bright colours, displaying brightly coloured jars and bottles, hanging from gold chains. This almost surreally jolly place, a sensation 
not normally given by a drugstore, suggests that it has enough supplies to heal the ill but it can also counterbalance the old neighbouring façades with their cracking surfaces. The drugstore advertising ordinary "Prescriptions", "Drugs", and the possibly vulgar "Ex-lax" shows that even the most unappealing places can be occasionally invested with redeeming qualities.

In the end, Hemingway's and Hopper's mundane scenes are not supposed to please the eye aesthetically but rather build disquieting narratives of modern life, that finally create powerful metaphors of silence, isolation, and emptiness.

\section{LIVING IN FRAGMENTATED PRIVATE AND PUBLIC INTERIORS}

The growing impersonality of the public places depicted in Hopper's paintings and Hemingway's short stories affects the individual's private world. These private spaces become as meaningless as the social world, empty, and morally heterogeneous. The transfer of visual interest to the interior happens for both aesthetical and psychological reasons: it renders the nature of individual experiences in the modern world and it replaces the view of the exterior with a realist aesthetic of interior spaces. For instance, in Automat (1927), Hopper depicts realistically and accurately the details of an automat, a self-service restaurant, where a woman, apparently the only client, is having a coffee late at night. Next to her there is an empty plate and an empty chair in front of her. There is little enthusiasm in the woman's gestures, which raises the question of why she is there alone, not accompanied by anyone so late at night. This intensified feeling of loneliness and emptiness, present in all the paintings analysed here so far, is heightened by the strange effect of the artificial light inside. Except for the two thin light lines, there is nothing else of the restaurant's interior reflected on the darkened glass windows. This does not afford a view outside and gives the sensation that the window is similar to a wall blocking the view and confining the woman to a seemingly sealed place. Even though the lonely man in Sunday is sitting outside, on the sidewalk, and the woman in Automat is inside, sitting at an empty table in a restaurant, they both seem to be in the centre of a deserted city.

The night scene from Nighthawks (1942), seen through the diner's glass window, conveys the same stifling feeling of being trapped, like in a hermetically sealed glasshouse. There is no visible exit or no way to enter the restaurant. The viewer has difficulty explaining how the clients have been able to get inside, which endows the scene with a sense of mystery. There is man and a woman sitting together and having a quite conversation while they are being served by a young waiter in a white cap, and then there is another man with his back to us. The viewer's attention is immediately caught by the long mahogany 
counter and the two silver coffee urns at the end of the diner, which receive a special whitish glow from the warm light inside. Also, there is a cash register in the shop window of a store just across the street that seems to be the only object the viewer can recognize. There is also a sign above the diner's window advertising cigars for 5 cents, which, together with the cash register, are the only indicators of the everyday American experience. They are reminiscent of a lifestyle the viewer can identify with, but, because these objects are so disconnected and isolated one from another, they amplify the feeling that this scene could happen anywhere. Moreover, the windows of the adjacent building, with their blinds half pulled down, give no sign of life and seem completely abandoned. However, if these signs and objects were all put together, they would fail to form a clear narrative but would only reveal unconnected images of loneliness and alienation. Outside, in the dark exterior, contrasting with the warm indoor light, there is a series of shadows on the sidewalk that intensifies the sense of silence.

If Hopper painted his Nighthawks in 1942, at the height of World War II, when citieswereliterarallyemptied out, Hemingway wrote his story“ $A$ Clean Well-Lighted Place"in 1933,in the wake of the war. He writes: "It was late and every one had left the café except an old man who sat in the shadow the leaves of a tree made against the electric light" (291), as if foreshadowing Hopper's abandoned city in Nighthawks. The unnamed character, a deaf old man, projected against the darkness of the night, sits quietly in the shadows and gives himself away to excessive drink, and only speaks when he makes his request to the bartender. The action is set in an empty Spanish café where the reader witnesses the quiet conversation between two waiters, who keep a close watch on their single client. As the closing time approaches, the younger waiter is preoccupied with his family life, and rushes home; because of that, he bluntly refuses the old man's request for another drink. Meanwhile, the other older waiter is more understanding towards the needs of their client: "They [the two waiters] sat together at a table that was close against the wall near the door of the café and looked at the terrace where the tables were all empty except where the old man sat in the shadow of the leaves of the tree that moved slightly in the wind" (Hemingway 291).

However, the story seems to revolve around the news retold by the young waiter who hears that "last week he [the old man] tried to commit suicide" (Hemingway 291). This means that the looming shadows of death, coupled with images of despair, loss, and emptiness, dominate the scenes in "A Clean Well-Lighted Place,” but they also anticipate a more generalised sense of nothingness and disillusionment. Many critics see this story as a nihilistic point in Hemingway's career, as it appeared in the 1933 collection Winner Take Nothing, a time of profound despair when even winners take 'nothing'. It is the 
concept of "nothingness" that has received detailed consideration in the critical interpretation of the story:

The word nothing (or nada) contains huge actuality. The great skill in the story is the development, through the most carefully controlled understatement, of the young waiter's mere nothing into the old waiter's Something - a Something called Nothing which is so huge, terrible, overbearing, inevitable and omnipresent that once experienced, it can never be forgotten. (Baker 124)

Other critics note that the three characters in the story meet nada without voicing it, even if they all experience nothingness in their very personal manner, and give individual responses to it. They are confronted with the emptiness and hollowness of their inner nothing. It can be argued then that "the shadow of nada looms behind much of Hemingway's fiction” (Hoffman 174). The parody-prayer uttered by the older waiter at the end of the story outlines a microcosm in which nada is the powerful force that dominates every aspects of the existence: "Our nada who art in nada, nada be thy name thy kingdom nada thy will be nada in nada as it is in nada. Give us this nada our daily nada and nada us our nada as we nada our nadas and nada us not into nada but deliver us from nada; pues nada." (Hemingway 294, italics in original) The character substitutes the word nada for all the key nouns or verbs to give a general sense of physical or metaphysical absence, as well as to show the absence of any source of power or authority, and most crucially, he signals the impossibility of escape from the situation of living in the nada.

With Hopper's Chop Suey (1929), the viewers's attention is drawn to the interior, as the large windows in the painting do not show the townscape outside, but function rather as limiting boundaries. The right window allows only the perception of a shiny red and white sign, with SUEY spelled in bulb lights. Restricting the view even more, the other window on the left side shows some geometrical shapes that could be painted on a house façade or might as well be a reflection of the sky. Disturbed by the strange geometry of the townscape, the viewer examines the interior space of this cheap Chinese restaurant, whose foreground is taken up by a table occupied by two women. While one of them is sitting with her back to us, the other one is fully visible but her rigid face does not show any of her feelings. She seems lost in her thoughts and inert in a world that shuts down all communication. Even though both these two women and the couple at the other table wish to engage in conversations, there is an almost visible language barrier between these puppet-like figures. They create an impression of concentration exclusively on themselves,uncharacteristic of real, lively communication. The subjects' natural need of communication cannot be satisfied in practice and, instead, metaphors of silence proliferate exponentially. These communication gaps are rendered 
pictorially by Hopper but they are also the central aspects of Hemingway's uneven textual surfaces.

The atmosphere of stillness in Chop Suey appears also in Hopper's "Compartment C" (1938) of a train car where a female passenger is travelling all by herself. The lone woman is engrossed in reading while the train makes its way across a landscape compounded by dark woods, a river, and a bridge. Through the open train window, the inside and outside spaces convey a tension between the intimate act of reading in which the woman is absorbed and the accurate geometry shaping the few objects inside and the natural elements outside (for instance, the rectangular window frame and the semi-circular arches of the stone bridge): "It is in fact the tension between the intimacy of his subject matter and the calculated, concealed geometry of his composition that produces the atmosphere of stillness and isolation,” argues art curator Henry Geldzahler (qtd. in Mamunes 32).

In "A Canary for One”(1927), Hemingway explores the theme of train journeys, with a couple taking a night train trip to Paris: "It was very hot in the train and it was very hot in the lit salon compartment. There was no breeze came through the open window" (Hemingway 252). They share their compartment with an American old lady who travels to her daughter and who fears that the train will go off the track. During the journey, the conversation is not between the unnamed couple, as it may be expected, but between the wife and the chatty American lady. In this short story, the prospect of failure looms over the marriage of two unnamed partners, but this version of events turns out to be a mental construct to be further explored as the last line of the story announces that the couple will "set up separate residences" (256): "We followed the porter with the truck down along the long cement platform beside the train. At the end was a gate and a man took the tickets. We were returning to Paris to set up separate residences” (Hemingway 256).

Despite the typical character of places such as railway compartments, stores, cafés, hotel rooms, diners, Hemingway and Hopper elevate these spaces to monumental edifices of everyday life. In these interiors, the subjects experience the fleeting nature of modern life.

\section{CONCLUSIONS}

Hopper's reaction, in his response to Hemingway's short story "The Killers," published in a magazine for which Hopper did illustration work, aims at the general shallow social criticism of that time:

It is refreshing to come upon such a honest piece of work in an American magazine, after wading through the vast sea of sugarcoated mush that makes up the most of our fiction. Of the concessions to popular prejudices, the side 
stepping of truth and the ingenious mechanism of trick ending there is no taint in this story. (qtd. in Gail Levin, 7).

What Hopper admires in Hemingway's fiction is exactly his ability to play off the superficial surface fixed by society in order to reach the deeper meaning of significance and individual experience. They both derive their artistic strength from the careful observation of the everyday, the visible, and the actual, but their real focus is on the investigation of the gaps and fissures discovered in the increasingly unpredictable modern life, in which "a coherent sense of the real has been lost” (Renner 91).

Nevertheless, it must be stated that Hemingway's and Hopper's affinity for a realist aesthetic is never merely a reproduction or a mimetic representation of reality. In truth, Hemingway has given us "a documented diagnosis of our age, [...] one of the most compelling symbols of a personal response to our age" (Warren 53), an age in which the American expatriates lived a dislocated life. These men and women living under the shadow of the war sought satisfaction in a new world, from which old values had already disappeared. Likewise, Hemingway's characters experience this loss of direction and are doomed to live in the shadow of moral and physical ruin. His tales of lost love, his stories of death and war are indicative of the harsh spaces his characters inhabit. Hemingway's interest in the lack of emotional interaction is evident in the representation of the couples in "Cat in the Rain" and "Hills like White Elephants."

Hopper, too, was drawing attention to the social setting to portray the tensions of modern life. Both these two modernist artists confronted the increasingly unattractive evidence of extreme urban change and showed the turmoil of the modern subject, who appeared diminished and small in relation to the larger environment. Hopper was drawn to cities with intriguing buildings and their mysterious interior life, with solitary figures absorbed in their own worlds of contemplation. The focus is always on the drama within these individuals. Hopper's cityscapes, dominated by uncanny silence, seen in the harsh glare of the electric light casting unnerving shadows, are loaded with significance. His nocturnal scenes from which figures are often removed entirely become empty settings into which are projected feelings of emptiness, isolation, and alienation. In his painted New York scenes with altered neighbourhoods, Hopper sees the "the psychological pulse of their time [that] yet speak for all time" (Levin 64).

\section{Works Cited}

Baer, Ulrich. Remnants of Song: Trauma and the Experience of Modernity in Charles Baudelaire and Paul Celan, Stanford: Stanford University Press, 2000. Print. 
Baker, Carlos. Hemingway, The Writer as Artist. Princeton: Princeton University Press, 1990. Print.

Brooker, Peter. Modernity and Metropolis: Writing, Film and Urban Formations. Houndmills, Basingstoke: Palgrave, 2002. Print.

Head, Dominic. The Modernist Short Story. Cambridge: Cambridge University Press, 1992. Print.

Hemingway, Ernest. The Collected Stories. London: Everyman's Library, 1995. Print.

Hoffman, K. Steven. "Nada and The Clean, Well-Lighted Place: The Unity of Hemingway's Short Fiction”. New Critical Approaches to the Short Stories of Ernest Hemingway. Ed. J. Benson. Durham \& London: Duke University Press, 1990, pp. 172-91. Print.

Keunen, Bart. "Living with Fragments.World Making in Modernist City Literature”. Modernism. Eds. Vivian Liska and Astradur Eysteinsson. Amsterdam/ Philadelphia: John Benjamins Publishing Company, 2007, pp. 271-91. Print.

Ickstadt, Heinz. "Making it New: Constructions of Modernism". A Companion to American Literature and Culture. Ed. Paul Lauter. Chichester, West Sussex, UK: Wiley-Blackwell Publishing, 2010, pp. 377-93. Print.

Levin, Gail. Edward Hopper. The Art and The Artist. New York \& London: W.W. Norton \& Company, 1980.

May, E. Charles. “The Nature of Knowledge in Short Fiction”. The New Short Stories Theories. Ed. Ch. May. Athens, Ohio: Ohio University Press, 1994,pp. 131-43. Print.

Mamunes, Lenora. Edward Hopper Encyclopedia. Jefferson, North Carolina: McFarland \& Company Publishers, 2011. Print.

O’Connor, Frank. The Lonely Voice: A Study of the Short Story. Cleveland and New York: World Publishing Company, 1963. Print.

Renner, Rolf Günter. Edward Hopper 1882-1967. Transformation of the Real. (English translation: Michael Hulse). Koln, Germany: Benedikt Taschen Verlag GmbH, 1990. Print.

Weinberg H., Barbara et al. American Impressionism and Realism. The Painting of Modern Life, 1885-1915. New York: The Metropolitan Museum of Modern Art, 1994. Print.

Warren, Robert Penn. “Ernest Hemingway”. Bloom's Modern Critical Views. Ernest Hemingway. Ed. Harold Bloom. Philadelphia: Chelsea House Publishers, 2005, pp. 24-54. Print. 